\title{
PENGARUH JENIS KATODA TERHADAP GAS HIDROGEN YANG DIHASILKAN DARI PROSES ELEKTROLISIS AIR GARAM
}

\author{
Munawar Alfansury Siregar* \\ Fakultas Teknik, Program Studi Teknik Mesin \\ Universitas Muhammadiyah Sumatera Utara \\ Email: munawaralfansury@umsu.ac.id \\ Khairul Umurani, Wawan Septiawan Damanik \\ Fakultas Teknik, Program Studi Teknik Mesin \\ Universitas Muhammadiyah Sumatera Utara \\ Email: khairulumurani@umsu.ac.id, wawanseptiawan@umsu.ac.id
}

\begin{abstract}
ABSTRAK
Proses elektrolisis air sedang dikembangkan untuk menghasilkan hidrogen. Namun, karena proses elektrolisis membutuhkan energi listrik sebagai pemicu reaksi, proses ini memberikan efisiensi yang relatif rendah. Proses elektrolisis berfungsi jika ketersediaan sumber energi listrik mudah diperoleh dengan harga murah. Pengujian dengan variasi jarak katoda dan anoda, campuran elektrolit dan jenis elektroda yang digunakan terus dikembangkan untuk mengurangi jumlah energi listrik yang digunakan dalam proses elektrolisis sehingga dapat diterapkan dalam kehidupan sosial, tetapi belum belum menuai hasil yang memuaskan. Penelitian ini menggunakan sumber arus baterai $12 \mathrm{~V}$, dan jarak yang telah ditetapkan pada katoda dan anoda ialah $80 \mathrm{~mm}, 120 \mathrm{~mm}$ dan 200 $\mathrm{mm}$. Jenis elektroda yang digunakan Stainless steel, Aluminium dan Tembaga, dengan jumlah campuran garam yang terlarut ialah 250 gram dalam lima liter air, atau 50 gram perliter air. Hasil dari pengujian, tekanan gas yang dihasilkan oleh elektroda yang berbahan stainless steel lebih tinggi dibandingkan oleh elektroda yang berbahan aluminium dan tembaga dan semakin dekat jarak elektroda maka tekanan gas yang dihasilkan semakin tinggi. Dengan menggunakan manometer tabung $\mathrm{U}$ tekanan gas hidrogen tertinggi diukur pada elektroda stainless steel pada sisi katoda jarak $80 \mathrm{~mm}$ sebesar $9733 \mathrm{~Pa}$. Sedangkan tekanan hydrogen pada elektroda aluminium pada sisi katoda $9246.8 \mathrm{~Pa}$, dan tekanan hidrogen terendah diukur pada elektroda tembaga 6034 $\mathrm{Pa}$. Hasil pengujian menunjukkan perbedaan tekanan dari setiap jenis elektroda.
\end{abstract}

Kata kunci: air garam, elektrolisis

\begin{abstract}
The electrolysis process of water is being developed to produce hydrogen. However, because the electrolysis process requires electrical energy as a trigger for a reaction, this process provides relatively low efficiency. The electrolysis process works if the availability of an electric energy source is easily obtained at a low price. Testing with variations in the distance of the cathode and anode, a mixture of electrolytes and types of electrodes used continue to be developed to reduce the amount of electrical energy used in the electrolysis process so that it can be applied in social life, but has not yet reap satisfactory results. This research, using a $12 \mathrm{~V}$ battery current source, with a fixed distance at the cathode and anode is $80 \mathrm{~mm}, 120 \mathrm{~mm}$ and $200 \mathrm{~mm}$. The type of electrodes used is Stainless steel, Aluminum and Copper, with the amount of salt dissolved 250 grams for five liters of water, or 50 grams per liter of water. Using a $U$ tube manometer, the highest hydrogen gas pressure measured on a stainless steel electrode on the cathode side at a distance of $80 \mathrm{~mm}$ is $9733 \mathrm{~Pa}$. Meanwhile, the hydrogen pressure on the aluminum electrode at the
\end{abstract}


cathode side is $9246.8 \mathrm{~Pa}$, and the lowest hydrogen pressure is measured on a $6034 \mathrm{~Pa}$ copper electrode. The test results show the pressure difference of each type of electrode.

Keywords: salt water, electrolyzed

\section{PENDAHULUAN}

Konsumsi energi global semankin meningkat setiap tahun sekitar $1.5 \%$ tercatat sejak 2010 dari jumlah keseluruhan energi yang dibutuhkan dan akan terus meningkat setiap tahunnya [1]. Darurat energi juga sudah disampaikan oleh pemerintah Indonesia melalui BPPT dengan alasan konsumsi bahan bakar yang terus meningkat setiap tahunnya dengan indikator produksi minyak bumi sejak 1991 terus mengalami penurunan. Pemerintah menargetkan pada tahun 2018 produksi minyak sekitar 800 ribu barel per hari, namun hingga akhir juli data Kementrian Energi dan Sumber Daya Mineral mengatakan bahwa produksi miyak masih sekitar 773 ribu barel, jumlah ini jauh dibawah tahun sebelumnya yang dapat mencapai 949 ribu barel per hari [2]. Kekhawatiran meningkatnya produksi $\mathrm{CO}_{2}$ juga menjadi perhatian karena membahayakan lingkungan tempat tinggal makhluk hidup semngkin terancam maka dibutuhkan sumber daya energi terbarukan seperti angin, matahari mapun energi yang berasal dari proses kimia yang ramah lingkungan [3]. Memisahkan unsur $\mathrm{H}_{2}$ dari $\mathrm{H}_{2} \mathrm{O}$ dengan proses elektrolisis reaksi Redoks menghasilkan hidrogen sebagai bahan bakar yang bersih dan ramah lingkungan untuk mesin pembakaran dalam merupakan salah satu solusi menjawab dari ketergantungan terhadap energi yang bersumber dari bahan fosil dan berbahaya. Gas hidrogen sangat baik digunkan sebagai bahan bakar karena memiliki sifat yang mudah terbakar dengan kepadatan energy gravimetric yang tinggi atau nilai kalor sekitar $142 \mathrm{MJ} / \mathrm{Kg}$ dan terrendah $120 \mathrm{MJ} / \mathrm{Kg}$ pada temperatur $25^{\circ} \mathrm{C}$ [4].

Elektrolisis merupakan proses elektrokimia dengan memanfaatkan energi listrik yang mengalir melalui katoda dan anoda didalam wadah yang berisi elektrolit. Dibutuhkan dua elektroda yang menghubungkan aliran listrik dari sumber arus agar terjadi rekasi kimia yaitu pada sisi positif disebut anoda dan pada sisi negative disebut katoda. Jenis anoda dan katoda diambil dari golongan logam yang bersifat netral seperti stainless steel. Reaksi yang dihasilkan akan berbeda jika kita menggunakan jenis elektroda yang berbeda, hal ini juga akan mempengaruhi produksi gas hidrogen yang dihasilkan. Ada tiga jenis elektroda yang akan digunkan pada penelitian ini yaitu stainless steel, aluminium dan tembaga. Gidon Amikam dkk 2018, memakai jenis elektroda Ni200 dengan luas $80 \mathrm{~cm}^{2}$ dengan ketebalan $2 \mathrm{~mm}$ dan $3 \mathrm{~mm}$ pada peneilitiannya melarutkan $\mathrm{NaCl} 85$ gram $/ \mathrm{kgH}_{2} \mathrm{O}$ dan $\mathrm{NaOH} 300$ gram $/ \mathrm{KgH}_{2} \mathrm{O}$ pada tempertur $30^{\circ} \mathrm{C}$ dan $50^{\circ} \mathrm{C}$, dengan focus terhadap jumlah energi listrik yang digunkan saat proses terjadi yaitu paling tinggi $467 \mathrm{~mA} / \mathrm{cm}^{2}$ dan terrendah $93.4 \mathrm{~mA} / \mathrm{cm}^{2}$ pada 5 hari pengoperasian sistem. Jun Chi 2018 ialah peneliti dari China melakukan proses elektrolisis pada minyak bumi dan menghasilkan gas hidrogen 100-3000 Nm33/jam [5]. Ena Marliana menambahkan $\mathrm{NaHCO}_{3}$ sebagai katalis dengan konsentrasi larutan 2,5\%-15\% dan menunjukkan tinggihnya jumlah pemakaian arus listrik hingga 280 watt jika konstrasi elektrolit ditambah [6]. Ditahun yang sama Widyanigrum 2016, juga melakukan pengujian alat elektrolisis Widya juga menambahkan natium bicarbonat $\left(\mathrm{NaHCO}_{3}\right)$ sebagai elektrolit, hasil menunjukkan pemakaian arus listrik sebesar 353,52 watt untuk menghasilkan gas brown 0,00123 L/s. dan efisiensi tertinggi 40,29\% [7]. Mardiasyah 2011, melakukan penambahan larutan entanol dan methanol kedalam elektrolit dan hasil menunjukkan jumlah produksi hidrogen meningkat hingga 5 kali dari sebelum penambahan dan mardiansyah juga mengatakan konsumsi aliran listrik juga akan meningkat jika konsentrasi larutan pada eleketrolit ditambah [8].

Banyak factor yang dapat mempengaruhi jumlah produksi gas hidrogen dalam proses air garam mulai dari jenis elektroda, jumlah konsentrasi larutan dan jarak elektroda. Kedepannya hidrogen sangat dibutuhkan sebagai energi komersial penggunaanya mengigat penggunaan hidrogen terus mengalami kenaikan setiap tahunnya dan produksinya juga saat ini sampai 45 juta metric ton meningkat $6 \%$ pertahun [9], dan hanya $4 \%$ produksi hidrogen dihasilkan dari proses 
elektrolisis air [10]. Besar kemurnian hidrogen hanya didapat dengan proses elektrolisis air hingga 99.999\% tanpa menggunakan bahan fosil dan nuklir yang merusak lingkungan [9,10]. Dengan dilakuakan penelitian ini diharapkan memberikan informasi terkait dengan jenis elektroda yang paling baik digunakan pada proses elektrolisis air garam dengan mengukur tekanan gas yang dihasilakan terhadap besar pemakaian arus listrik selama pengujian.

\section{METODOLOGI DAN MATERIAL}

\subsection{Reaksi Kimia Pada Air}

Proses dekompresisi air menjadi oksigen dan hidrogen dengan menggunakan arus listrik yang mengalir melalui air. Energi listrik di gunakan untuk memecah ikatan molekul air $\mathrm{H}_{2} \mathrm{O}$ menjadi molekul $\mathrm{H}_{2}$ dan $\mathrm{O}_{2}$.Selanjutnya ion-ion $\mathrm{O}_{2}$ berimigrasi melewati membran elektrolit untuk mencapai sisianoda sesuai prinsip fisiska electron hole. Setelah mencapai sisi anoda ion-ion $\mathrm{O}_{2}$ akan melepaskan elekron dan membentuk molekul oksigen dan pada sisi katoda akan memebentuk molekul hidrogen. Reaksi kimia yang terjadi pada proses elektrolisis air dapat dilihat pada persamaan (1), proses elektrokimia oksigen dan hidrogen pada sisi anoda pada persamaan (2) dan proses elektrokimia gas hidrogen dan oksigen pada sisi katoda persamaan (3) berikut $[8,11,12]$.

$$
\begin{aligned}
& \mathrm{H}_{2} \mathrm{O} \rightarrow \mathrm{H}_{2(g)}+0.5 \mathrm{O}_{2(g)} \\
& 2 \mathrm{OH}^{-} \rightarrow 0.50_{2}+\mathrm{H}_{2} \mathrm{O}+2 e^{-} \\
& 2 \mathrm{H}_{2} \mathrm{O}+2{ }_{e} \rightarrow \mathrm{H}_{2}+2 \mathrm{OH}
\end{aligned}
$$

Selama proses elektolisis, energi listrik diubah menjadi energi kimia untuk mendapatkan gas hidrogen. Jika melarutkan $\mathrm{Cl}$ pada elektrolit maka gas yang dihasilkan tidak hanya berupa hidrogen melainkan akan muncul senyawa baru yaitu Clorin dan persamaan kimianya juga telah berubah dari sebelumnya dan reaksi yang terjadi pada anoda dapat dilihat dalam persamaan (4) berikut $[13,12]$.

$$
2 \mathrm{Cl}^{-} \rightarrow \mathrm{Cl}_{2(g)}+2 e^{-}
$$

Klorin yang dihasilkan selanjunya diserap dalam larutan air dengan $\mathrm{PH}>3$ melalui reaksi yang ditunjukkan pada persamaan (5) dan (6).

$$
\begin{aligned}
& \mathrm{Cl}_{2(g)}+\mathrm{H}_{2} \mathrm{O} \leftrightarrow \mathrm{HOCl}+h^{+}+\mathrm{Cl}^{-} \\
& \mathrm{Cl}_{2}+\mathrm{OH}^{-} \leftrightarrow \mathrm{HOCl}+\mathrm{Cl}^{-}
\end{aligned}
$$

Menurut PH dari asam hipoklorit dan ion hipoklorit $\mathrm{PH}>7.46$ terbentuk dari persamaan (7) sebagai berikut.

$$
\mathrm{HOCl} \leftrightarrow \mathrm{H}^{+}+\mathrm{OCl}^{-} \quad K_{a}=10^{-7.46}
$$

Gas klorin yang diproduksi secara elektrokimia kemungkinan dioksidasi menjadi klorat dianoda, direduksi menjadi bentuk klorida pada sisi katoda, atau diubah secara kimia menjadi klorat [15]. Secara teori air yang bercampur degan $\mathrm{NaCl}$ persamaan kimianya akan berubah 
membentuk senyawa baru, gas oksigen yang dihasilkan pada proses elektrolisis air garam tidak ada karna air telah bercampur terhadap $\mathrm{NaCl}$, jadi gas yang di hasilkan pada sisi anoda ialah gas klorin $\mathrm{Cl}_{2}$, dan pada sisi katoda $\mathrm{H}_{2}$, persamaan reaksi yang terjadi jika air bercampur dengan $\mathrm{NaCl}$ dapat dilihat pada persamaan (8) berikut.

$$
2 \mathrm{Nacl}_{(a q)}+2 \mathrm{H}_{2} \mathrm{O}(1) \rightarrow 2 \mathrm{NaOH}_{(a q)}+\mathrm{H}_{2(g)}+\mathrm{Cl}_{2(g)}
$$

Pengukuran gas yang keluar dari saluran ke tabung manometer $\mathrm{U}$ dengan menggunakan persamaan (9) berikut akan dihitung tekanannya.

$$
P=\rho \times g \times h
$$

\subsection{Proses Pengerjaan}

Dengan menggunakan tabung pipa air diameter 3 in sebagai setasiun proses dan wadah elektrolit dengan panjang $500 \mathrm{~mm}$ dan jarak antra katoda dan anoda diberi 3 variasi $80 \mathrm{~mm}, 120$ $\mathrm{mm}$ dan $200 \mathrm{~mm}$ dengan diberi pembatas sebagai pemisah gas yang dihasilkan saat proses berlangsung dengan bahan tembaga sebagai penghantar yang baik. Dimensi elektroda tembaga, stainless steel dan aluminium yang digunakan 60 x $50 \mathrm{~mm}$ dan tebal $1.5 \mathrm{~mm}$. Gambar dari ketiga jenis elektroda yang digunakan dapat dilihat pada Gambar.1.

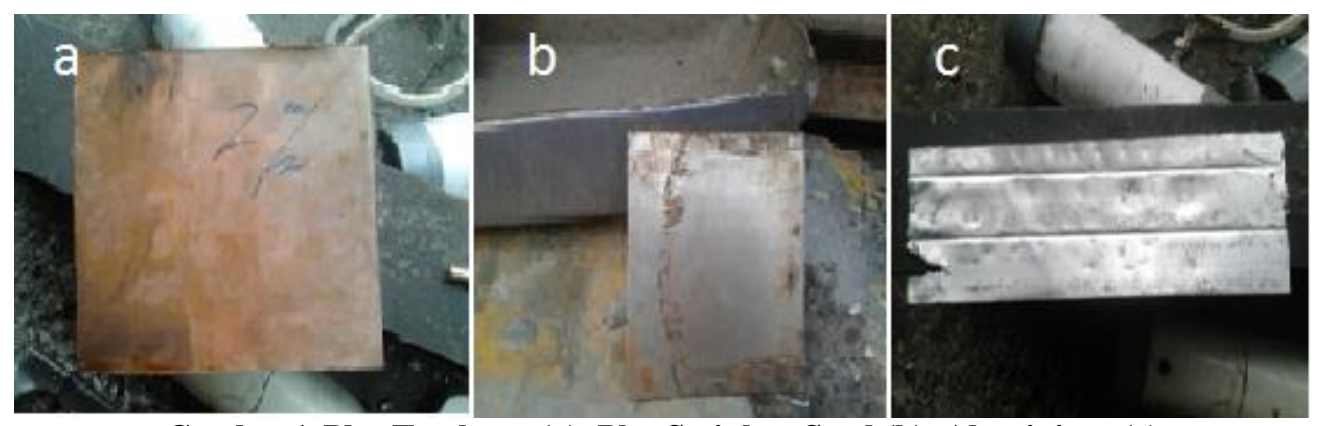

Gambar 1. Plat Tembaga (a), Plat Stainless Steel (b), Aluminium (c)

Dari ketiga jenis eketroda masing-masing memiliki daya hantar yang baik atau bersifat konduktor yang baik. Tidak semua jenis material dapat digunakan sebagai elektroda jika tidak memenuhi standart sebagai penghantar yang baik. Plat elektroda dipasang dibawah tabung reaksi dan dan direkatkan dengan menggunakan lem agar air tidak bocor saat proses elektrolisis berjalan. Kemudian garam dapur (NaCL) dilarutkan sebanyak 50 gram perliter air dan di aduk secara merata sebelum dimasukkan kedalam tabung reaksi. Arus listrik yang digunakan bersumber dari AKI $12 \mathrm{~V} 70 \mathrm{~A} / \mathrm{h}$ yang sisi negatifnya dihubungkan ke sisi katoda dan sisi positif batrai dihubungkan ke anoda. Gas hidrogen akan keluar dari sisi katoda dan menekan kesegala arah pada ruang reaksi dan jika telah memenuhi ruangan maka akan mengalir keluar dengan selang yang dipasangkan pada sisi atas tabung reaksi begitu juga pada sisi anoda telah dipasng saluran yang akan membawa gas klorin kluar dari tabung reaksi. Air dimasukkan sampai keseluruhan permukaan elektroda terendam air elektrolit dan setelah batasnya maka saluran masuk elektrolit ditutup agar gas hidrogen dan klorin yang memenuhi ruangan tabung reaksi tidak terbuang kelingkungan.

Setiap satu elektroda dialakukan pengujain sebanyak 3 kali pengambilan data dalam waktu 60 detik dan akan diambil rata-rata tekanan gas yang di peroleh. Pengukuran tekanan gas 
dilakukan dengan menghubungkan ujung salurann gas hidrogen dan klorin ke tabung manometer $\mathrm{U}$ yang berisi air dengan memberi ukuran skala permukaan air mula-mula sebelum terdorong gas dan mengukur ketinggian air pada tabung manometer $\mathrm{U}$ setelah terdorong gas.

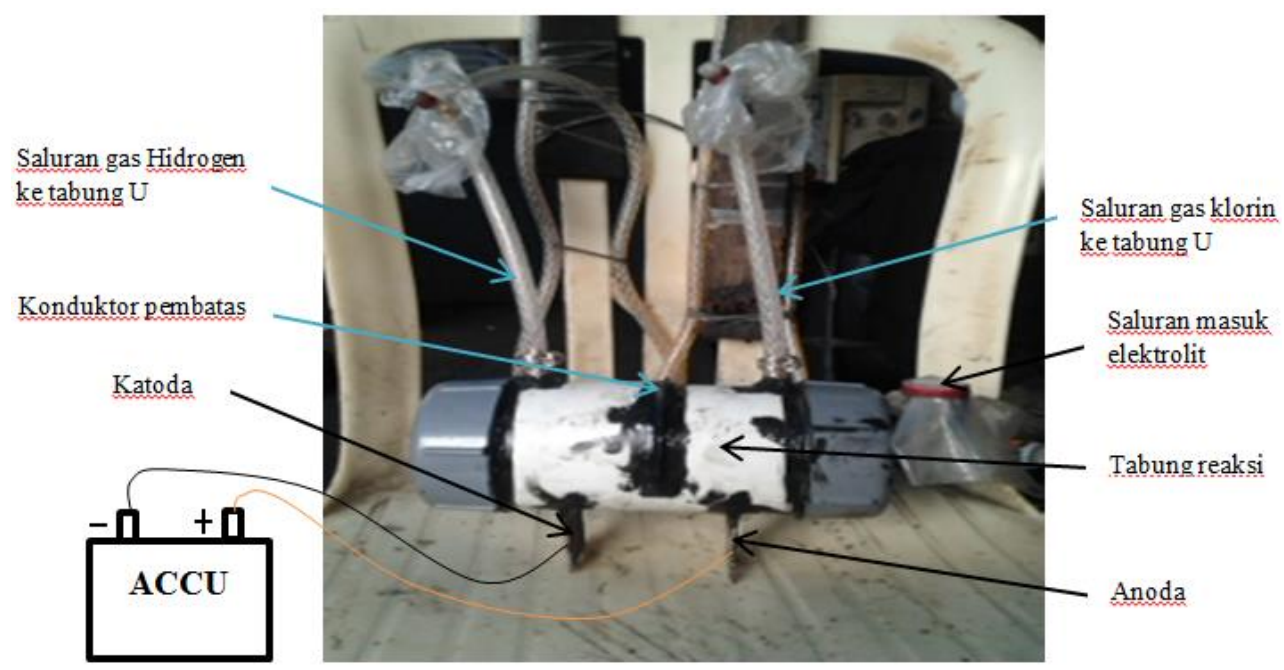

Gambar 2. Eksperimental Tabung Reaksi

Bahan konduktor pembatas tembaga selain sebagai penghantar listrik yang baik juga sebagai pembatas gas yang akan keluar ke saluran masing-masing untuk menuju ke tabung manometer $\mathrm{U}$ agar tekanan gas dapat diukur. Air yang tadinya hanya bersifat semi konduktor akan berubah setelah diberi ion-ion yang berasal dari priodik no.1 yang banyak mengandung mineral penghantar yang baik sehingga daya antar listrik air menjadi meningkat. Skema dan cara kerja alat dijelaskan pada Gambar 3.

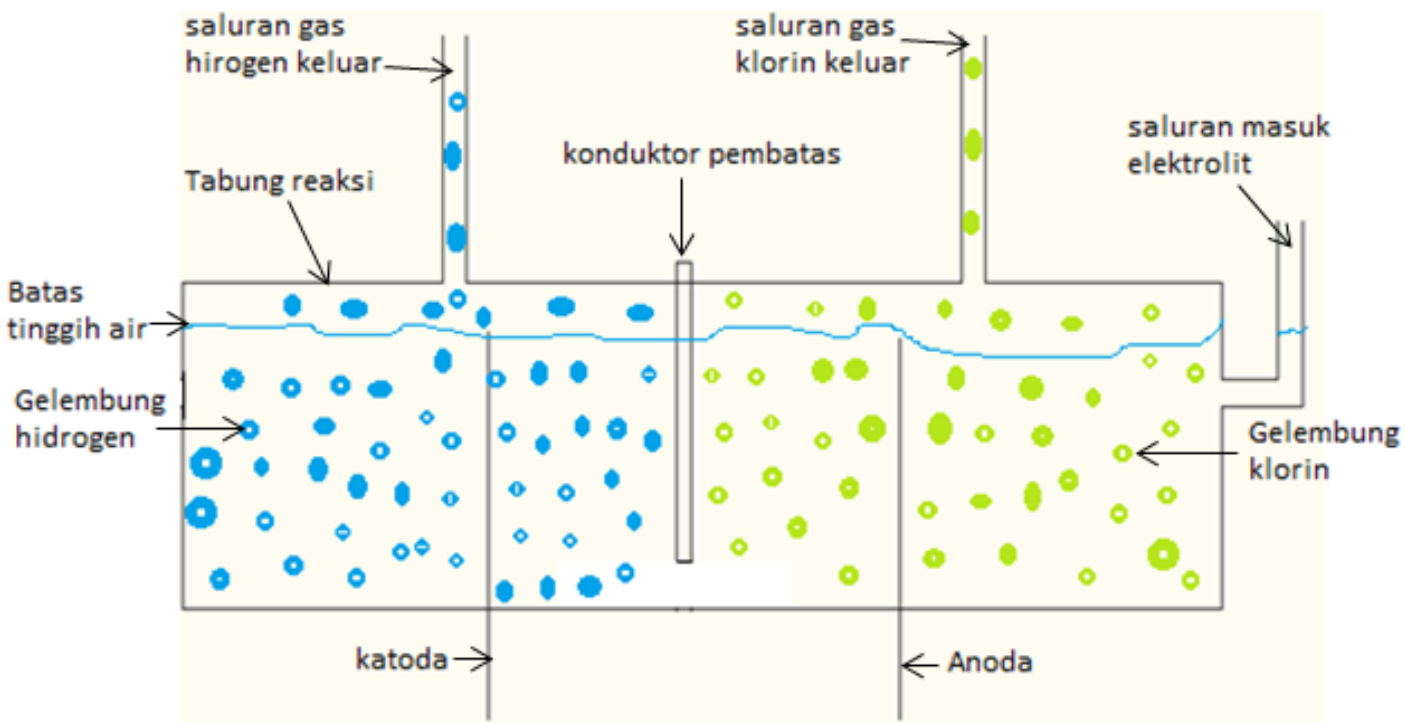

Gambar 3. Skema dan Proses Kerja Alat Elektrolisis 
Dari Gambar 3 dapat dilihat cara kerja pembatas yang hanya membatasi ruang terkumpulknya gas hidrogen dan klorin yang dihasilkan pada saat proses berlangsung. Sementara bagian sisi dasar tabung tidak penuh tertutup pembatas konduktor sehingga saluran masuk elektrolit hanya membutuhkan satu sisi saja. Saluran masuk elektrolit akan ditutup jika air sudah mencapai batas yang ditentukan sampai tidak ada kebocoran.

\section{HASIL DAN PEMBAHASAN}

Setelah dilakukan percobaan dari ketiga jenis elektroda Stainless steel, tembaga dan aluminium, tekanan gas yang diukur pada katoda stainless stell yang paling besar dan yang paling terkecil pada katoda tembaga. Perbedaan-perbedaan tersebut dapat dilihat pada Tabel.1 dibawah ini.

Tabel 1. Tekanan gas pada sisi katoda dan anoda

\begin{tabular}{ccccccc}
\hline \multirow{2}{*}{ Jarak } & \multicolumn{2}{c}{ Stainless steel $(\boldsymbol{P a})$} & \multicolumn{2}{c}{ Aluminium $(\boldsymbol{P a})$} & \multicolumn{2}{c}{ Tembaga $(\boldsymbol{P a})$} \\
\cline { 2 - 7 } & Katoda & Anoda & Katoda & Anoda & Katoda & Anoda \\
\hline \multirow{2}{*}{$80 \mathrm{~mm}$} & 9733 & 9246 & 9246 & 9052 & 6034 & 5840 \\
$120 \mathrm{~mm}$ & 6540 & 7838 & 6138 & 7106 & 4876 & 4104 \\
$200 \mathrm{~mm}$ & 5937 & 6326 & 4551 & 4560 & 3654 & 3045 \\
\hline
\end{tabular}

Pada Tabel.1 dapat dilihat bahwa tekanan gas yang diukur pada proses elektrolisis terbesar pada jenis elektroda stainless steel, dan selanjutnya kedua tertinggi diikuti jenis elektroda aluminium dan tekanan gas yang terrendah diukur dari jenis elektroda tembaga. Sedangkan untuk kedua sisi elektroda pada masing-masing jenis tekanan gas yang paling tinggi diukur pada sisi katoda. Semakin rapat jarak dari katoda dan anoda maka semakin tinggi pula tekanan gas yang akan terukur saat proses elektrolisis dilakukan dalam waktu yang sama. Tinggi rendahnya dari setiap jenis, sisi dan jarak dapat dilihat pada Gambar 4.

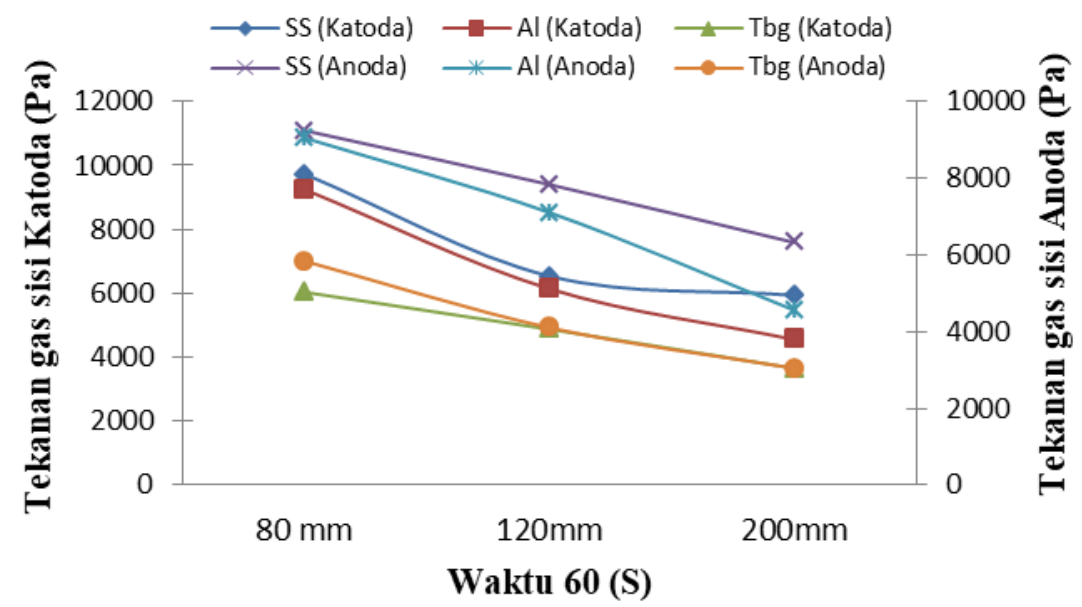

Gambar 4. Grafik Tekanan Gas Untuk Setiap Elektroda

Tekanan gas hidrogen yang tertinggi pada jenis elektroda stainless stell yaitu pada sisi katoda sebesar $9733 \mathrm{~Pa}$ pada jarak $80 \mathrm{~mm}$, dan pada sisi anoda $9246 \mathrm{~Pa}$, dan selanjutnya disusul pada jenis elektroda stainless stell dengan tekanan gas tertinggi pada sisi katoda $9246 \mathrm{~Pa}$, dan sisi anoda $9052 \mathrm{~Pa}$ pada jarak $80 \mathrm{~mm}$, sedangkan tekanan gas terrendah yang diproleh dari ketiga jenis 
elektroda ialah pada jenis tembaga yaitu pada sisi katoda sebesar $6034 \mathrm{~Pa}$, dan sisi anoda $5840 \mathrm{~Pa}$. Tekanan gas akan menurun jika jarak katoda dan anoda diperpanjang dan begitu juga pemakaian arus listrik juga akan semakin sedikit pada jarak anoda $200 \mathrm{~mm}$ dan tertinggi pada jarak $80 \mathrm{~mm}$, dan ini berpengaruh terhadap temperatur elektrolit yang berada pada wadah penampung, sehingga temperatur akan naik lebih cepat jika jarak katoda dan anoda diperdakat. Hasil pengujian terhadap temperatur dan arus listrik yang terpakai dapat dilihat pada tabel 2.

Tabel 2. Jenis Katoda terhadap kuat arus dan temperatur elektrolit

\begin{tabular}{ccccccc}
\hline \multirow{2}{*}{ Jarak } & \multicolumn{2}{c}{ Stainless steel } & \multicolumn{2}{c}{ Aluminium } & \multicolumn{2}{c}{ Tembaga } \\
\cline { 2 - 7 } & Arus $(\boldsymbol{A})$ & $\begin{array}{c}\text { Temperatur } \\
\left({ }^{\boldsymbol{C}} \boldsymbol{C}\right)\end{array}$ & $\begin{array}{c}\text { Arus } \\
(\boldsymbol{A})\end{array}$ & $\begin{array}{c}\text { Temperatur } \\
\left({ }^{\boldsymbol{C}} \boldsymbol{C}\right)\end{array}$ & $\begin{array}{c}\text { Arus } \\
(\boldsymbol{A})\end{array}$ & $\begin{array}{c}\text { Temperatur } \\
\left({ }^{\boldsymbol{O}} \boldsymbol{C}\right)\end{array}$ \\
\hline \multirow{2}{*}{$80 \mathrm{~mm}$} & 30 & 37 & 27 & 33 & 18 & 31 \\
$120 \mathrm{~mm}$ & 21 & 32 & 14 & 31 & 7 & 30 \\
$200 \mathrm{~mm}$ & 10 & 30 & 8 & 29 & 3 & 29 \\
\hline
\end{tabular}

Kuat arus tertinggi pada jenis eklektroda stainless steel pada jarak $80 \mathrm{~mm}$ sebesar $30 \mathrm{~A}$, dan selanjutnya disusul jenis elektroda aluminium pada jarak $80 \mathrm{~mm}$ sebesar $33 \mathrm{~A}$ dan arus terrendah pada jenis elektroda tembaga sebesar 18 A pada jarak $80 \mathrm{~mm}$. Semakin jauh jarak katoda dan anoda maka semakin kecil pula arus listrik yang terpakai saat proses elektrolisis berlangsung. Begitu juga untuk temperatur tertinggi pada jenis elektroda stainless stell sebesar $37^{\circ} \mathrm{C}$ disusul dengan elektroda jenis aluminium sebesar $33^{\circ} \mathrm{C}$ dan terrendah pada elektroda jenis tembaga $31^{\circ} \mathrm{C}$ dengan jarak yang sama $80 \mathrm{~mm}$. Tinggi rendahnya dapat jumlah arus dan temperatur pada saat pengujian dapat dilihat pada Gambar 5.

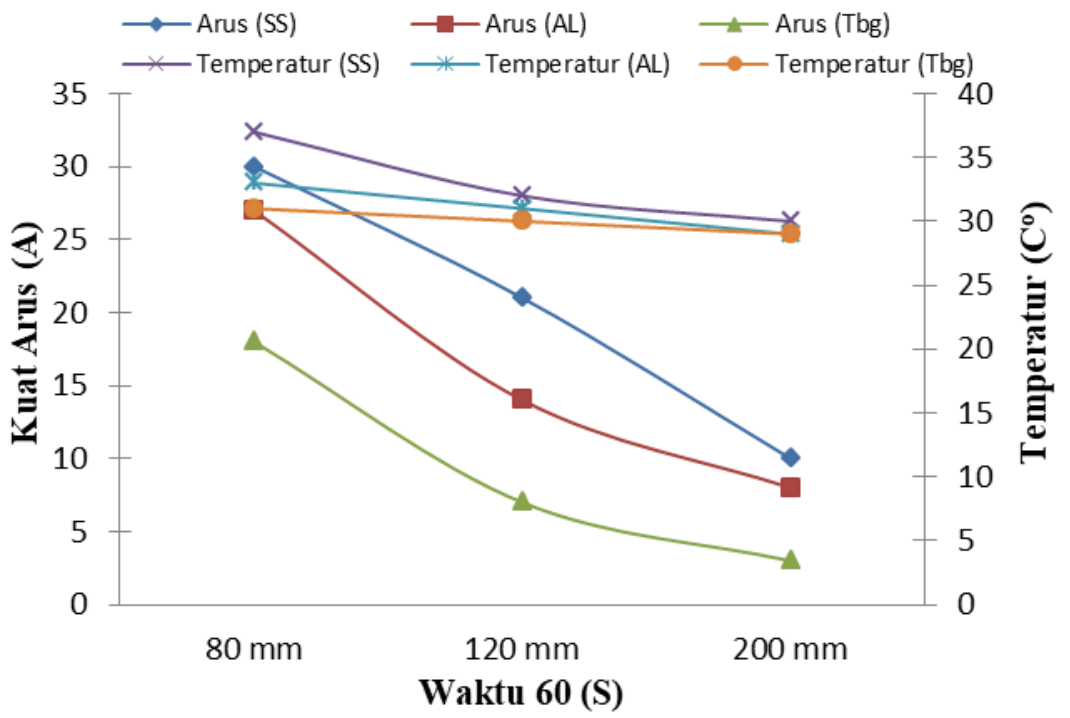

Gambar 5. Grafik Kuat Arus dan Temperatur Elektolit

Pada garis temperatur di grafik dapat dilhat tidak terlalu jauh jaraknya dari ketiga jenis elektroda sehingga dapat disimpulkan kenaikan temperatur akan cepat jika jarak anatara katoda dan anoda di perdekat. Sementara kuat arus yang terpakai dari ketiga jenis elektroda sangat berbeda dan naik turunnya juga seragam dengan jarak antara katoda dan anoda yang diberikan. 


\section{KESIMPULAN}

Dari hasil pengujian dan pembahasan diperoleh kesimpulan dari proses elektrolisis air garam dengan menggunakan tiga jenis elektroda yaitu stainless steel, aluminium dan tembaga sebagai berikut.

1. Tekanan gas hidrogen yang paling tinggi pada jenis elektroda stainless steel pada sisi katoda $9733 \mathrm{~Pa}$, dan gas klorin sisi anoda $9246 \mathrm{~Pa}$, menyusul pada jenis elektroda aluminium gas hidrogen pada sisi katoda sebesar $9246 \mathrm{~Pa}$, dan gas klorin pada sisi anoda $9052 \mathrm{~Pa}$, dan produksi gas terrendah pada jenis elektroda tembaga dengan gas hidrogen sisi katoda sebesar $6034 \mathrm{~Pa}$, dan gas klorin pada sisi anoda sebesar $5840 \mathrm{~Pa}$.

2. Kuat arus yang mengalir dan dipakai saat proses elektrolisis berlangsung juga tertinggi pada jenis elektroda stainless steel sebesar $30 \mathrm{~A}$, dan menyusul jenis elektroda aluminium sebesar 27 A dan terrendah pada jenis tembaga 18 A dengan jarak yang sama $80 \mathrm{~mm}$.

3. Temperatur elektrolit pada ruang reaksi juga seperti sebelumnya yang paling tinggi pada elektroda jenis stainless steel, aluminium selanjutnya yang terrendah pada jenis elektroda tembaga pada jarak katoda dann anoda $80 \mathrm{~mm}$.

4. Semua pengaruh yang terjadi pada jumlah produksi gas, kuat arus dan temperatur elektrolit berkaitan dengan jarak katoda dan anoda.

\section{DAFTAR PUSTAKA}

[1] BP Statistical Review of World Energy, 2019. BP, from, https://www.bp.com/content/dam/bp/ business- sites/en/global/corporate/pdfs/energyeconomics/statistical-review/bp-stats-review-2019-full-report.pdf, diakses tanggal 13 Oktober 2019.

[2] Amikam G, et al.,2018, Chlorine-free alkaline seawater electrolysis for hydrogen production, International Journal of Hydrogen Energy

[3] BPPT Indonesia Darurat Energi, 2019, https://www.bppt.go.id/teknologi-informasi-energidan-material/3296-bppt-indonesia-darurat-energi.

[4] M.Hasanuzzaman, Zubir US, Ilham NI, Che HS, 2017, Global electricity demand, generation, grid system, and renewable energy polices: a review. Wiley Interdiscipl Rev Energy Environ ;6(3):1e18.

[5] Chi J, Hongmei Y, 2018, Water electrolysis based on renewable energy for hydrogen production, Chinese Journal of Catalysis 39, hal;390-394.

[6] Marliana E, Wahyudi S, Yuliati L, 2013, Produksi Brown's gas hasil elektrolisis $\mathrm{H}_{2} \mathrm{O}$ dengan katalis $\mathrm{NaHCO}_{3}$, Jurnal Rekayasa Mesin Vol.4, No.1 hal:53-58.

[7] Widhiyanuriyawan D, 2016, Performance of Distilled Water Electrolysis with adding of Sodium Bicarbonate as Catalytic, Trans Tech Publications, Switzerland, Vol. 836, pp 294298.

[8] Mardiansyah, 2011, sistem produksi hidrogen melalui proses elektrolisis plasma nonthermal dalam larutan elektrolit KOH dengan penambahan methanol dan etanol, Skripsi, Fakultas Teknik/Program Studi Teknik Kimia, Universitas Indonesia, Depok.

[9] Eurochlor. Chlorine industry review 2017. http:// www.eurochlor.org/download-centre/thechlorine-industryreview. Aspx 201-2017, diakses tanggal 13 Oktober 2019.

[10] Karlsson RKB, Cornell A, 2016, Selectivity between oxygen and chlorine evolution in the chlor-alkali and chlorate processes. Chem Rev ;116(5):2982e3028. 
[11] A Ursua, Gandia LM, Sanchis P, 2012. Hydrogen production from water electrolysis: current status and future trends. Proc IEEE;100(2):410e26.

[12] M Rudolf, I Rousar, J Krysa, 1995. Cathodic reduction of hypochlorite during reduction of dilute sodium chloride solution. J Appl Electrochem;25:155e65.

[13] M Carmo, DL. Fritz, Mergel J, Stolten D,2013. A comprehensive review on PEM water electrolysis. Int J Hydrogen Energy;38:4901e34. 